\title{
Mitigating discard mortality from dusky flathead Platycephalus fuscus gillnets
}

\author{
Matt K. Broadhurst ${ }^{1, *}$, Russell B. Millar ${ }^{2}$, Craig P. Brand ${ }^{1}$ \\ ${ }^{1}$ New South Wales (NSW) Department of Primary Industries, Fisheries Conservation Technology Unit, PO Box J321, \\ Coffs Harbour, New South Wales 2450, Australia \\ ${ }^{2}$ Department of Statistics, The University of Auckland, Private Bag 92019, Auckland, New Zealand
}

\begin{abstract}
The mortalities and contributing parameters were estimated for key species discarded during commercial gillnetting (80 $\mathrm{mm}$ mesh) targeting dusky flathead Platycephalus fuscus in a southeastern Australian estuary. Bycatches (1470 individuals from 16 species over 11 deployments) were assessed for their immediate mortalities onboard the gillnetter, before subsamples (570 individuals from 11 species) were discarded into cages and monitored for their short-term fate over $4 \mathrm{~d}$. Appropriate controls were concurrently caged and monitored. Blood samples were taken from some live meshed-and-discarded yellowfin bream Acanthopagrus australis and luderick Girella tricuspidata and analysed for plasma cortisol and glucose. Concomitantly angled fish were similarly sampled (to provide baseline estimates of blood physiology). The immediate mortalities of the abundant species ranged between 0 (undersize blue swimmer crab Portunus pelagicus $<6 \mathrm{~cm}$ carapace length) and $70 \%$ (undersize $P$. fuscus $<36 \mathrm{~cm}$ total length [TL]). Water temperature had a statistically significant positive relationship with the immediate mortality of $G$. tricuspidata and large-tooth flounder Pseudorhombus arsius, and TL had a significant negative relationship with the immediate mortality of black sole Synaptura nigra. Compared to baseline estimates, mean plasma cortsiol concentrations in meshed-and-discarded G. tricuspidata and A. australis were significantly greater, and approached levels comparable to most teleosts after peak stress. Mean glucose concentrations were not concomitantly elevated, possibly reflecting limited time between stress and sampling for some individuals. Short-term mortalities occurred throughout the entire $4 \mathrm{~d}$ monitoring period for most species and ranged from 0 (yellowfin leatherjacket Meuschenia trachylepis) to $29 \%$ (A. australis). Water temperature and TL were identified as having significant impacts similar to those described above on the delayed fate of A. australis and G. tricuspidata. The partitioned mortalities were combined to provide estimates of overall mortality $( \pm \mathrm{SE}$ ) for the main species that ranged between $5.9 \pm 3.3 \%$ (P. pelagicus) and $76.9 \pm 7.8 \%$ (undersize $P$. fuscus). Discard mortality in this fishery could be mitigated by allowing fishers to retain a small percentage of undersize $P$. fuscus, restricting the deployment of nets in water temperatures $>16$ to $17^{\circ} \mathrm{C}$, and encouraging the careful removal of catches from meshes.
\end{abstract}

KEY WORDS: Gillnet $\cdot$ Bycatch $\cdot$ Discards $\cdot$ Mortality $\cdot$ Unaccounted fishing mortality

\section{INTRODUCTION}

Gillnets are the most commonly used commercial fishing gear in New South Wales (NSW) estuaries, deployed by more than 480 fishers to catch up to $2200 \mathrm{t}$ of mostly teleosts valued at AU\$ 8.3 million per annum, or approximately half of the total estuarine harvest. Retained catches comprise more than 40 species, but are dominated (>85\%) by fewer than 10 sparids, sillaginids, gerreids, girellids, platycephalids, and mugilids (Gray 2002, Gray et al. 2004, 2005a).

As with all NSW commercial fishing gears, gillnets are regulated by various input controls (including general temporal and spatial limits on their use, and specific restrictions on mesh sizes, headline lengths and fishing heights), all of which vary with unregulated 
factors (such as twine diameter $-\varnothing$, material and hanging ratios) according to the species being targeted (Gray 2002, Gray et al. 2004, 2005a, 2005b). While there are considerable differences among the types and designs of gillnets used in NSW, most can nevertheless be separated into 4 broad categories according to their deployment and the main species sought. These configurations include (1) gillnets with low fishing heights $(<0.8 \mathrm{~m})$ set overnight on the bottom to target dusky flathead Platycephalus fuscus, and other, deeperwalled $(>2 \mathrm{~m}$ ) nets to catch more vertically distributed species that are either (2) deployed and immediately retrieved at any time of the day, or nocturnally deployed for up to (3) 3 or (4) $12 \mathrm{~h}$ (overnight). In general, the immediate and $3 \mathrm{~h}$ retrieval of gillnets (Methods 2 and 3 ) are permitted throughout the year, mainly targeting sea mullet Mulgil cephalus, while overnight deployments (Methods 1 and 4) are restricted to between April and October, during which time the deeperwalled configurations are used to catch both species above, but also luderick Girella tricuspidata and yellowfin bream Acanthopagrus australis. Irrespective of their deployment, nearly all gillnets are between 375 and $1450 \mathrm{~m}$ in length, and typically fished by 1 person from a powered dory.

In recent years, concerns over the discarding of unwanted catches (termed 'bycatch') by NSW gillnetters, and the potential for associated negative impacts on the stocks of important species, resulted in fisherydependant surveys to firstly quantify bycatches (Gray 2002, Gray et al. 2004, 2005a), and then examine technical solutions to improve the selectivity of problematic gillnet configurations (Broadhurst et al. 2003, Gray et al. 2004). Because gillnets typically select fish across a narrow range of sizes (see Hamley 1975 for a review), much of the latter work simply involved increasing the existing minimum size of mesh $(80 \mathrm{~mm}$ in most configurations) to correspond to the maximum girth of legalsized individuals of the key targets (Broadhurst et al. 2003). Based on a clear negative relationship between the catches of undersize Acanthopagrus australis and Girella tricuspidata (both $<25 \mathrm{~cm}$ total length [TL]) and the size of mesh, the minimum was increased to $95 \mathrm{~mm}$ for deep-walled configurations deployed for longer than $3 \mathrm{~h}$ (Gray et al. 2005a).

While $95 \mathrm{~mm}$ mesh has reduced the bycatches of many gillnetters, $80 \mathrm{~mm}$ is still permitted in nets that are either set and retrieved within $3 \mathrm{~h}$ to catch Mugil cephalus, or left overnight to target Platycephalus fuscus, primarily because these fish have much narrower girths at their minimum legal sizes (MLS; 30 and $36 \mathrm{~cm}$ $\mathrm{TL}$, respectively) than other important species, including Acanthopagrus australis and Girella tricuspidata. Consequently, at times at least some proportions of the catches from $80 \mathrm{~mm}$ nets are discarded, including juveniles of the above economically important species, as well as yellowfin leatherjacket Meuschenia trachylepis, flounders Pseudorhombus spp. and black sole Synaptura nigra (Gray et al. 2004, 2005a).

There are few apparent gear-based solutions and/or spatial and temporal restrictions to the deployment of $80 \mathrm{~mm}$ gillnets in NSW which will allow catches of the various target species and their sizes to be maintained at current levels, while reducing bycatches (Broadhurst et al. 2003, Gray et al. 2005b). One remaining approach that may have some application is to examine changes to operational and/or post-capture handing procedures that minimise the mortality of bycatch, and therefore the negative impacts on their stocks due to discarding (Buchanan et al. 2002, Bettoli \& Scholten 2006).

Broadhurst et al. (2008a) provided support for the latter approach during recent work to quantify the short-term (<5 d) mortalities of juvenile Acanthopagrus australis ( $42 \%$ ) and blue catfish Neoarius graeffei $(11 \%)$ discarded from $80 \mathrm{~mm}$ mesh gillnets deployed and immediately retrieved in one NSW estuary. Fatalities of A. australis were higher for smaller individuals and were attributed in part to the way they were removed from meshes, which involved being pulled forwards so that the pressure of the mesh caused scale loss, and possibly damaged internal organs. The only predictor of mortality for $N$. graeffei was the presence of jellyfish Catostylus sp. (owing to their stinging nematocysts) during fishing. Simply carefully removing meshed $A$. australis and avoiding deploying the net during high abundances of jellyfish were recommended as appropriate strategies for significantly reducing discard mortality (Broadhurst et al. 2008a).

No similar work has been done for $80 \mathrm{~mm}$ gillnets set overnight to target Platycephalus fuscus. At present, this fishery is limited to approximately 40 operators working in 4 coastal lagoons (Wallis, Smiths, Tuggerah and Illawarra lakes). Fishing is restricted to between April and October, mainly to avoid reproductively active $P$. fuscus during summer, but also because of the belief that the survival of discards is higher in winter (Gray 2002, Gray et al. 2005a). Historically, to discourage $P$. fuscus gillnetters from targeting more valuable species, including Acanthopagrus australis (and catching their juveniles), they have been required to discard all organisms other than legal-sized $P$. fuscus and blue swimmer crab Portunus pelagicus ( $>6 \mathrm{~cm}$ carapace length [CL]). More recently, the lack of any information describing the fate of these discards, but the assumption of at least some fatalities (and associated wastage), resulted in a proposal to allow fishers to retain legal-sized individuals of several other economically important species. Irrespective of this potential amendment to regulations, undersize fish will still be discarded with unknown mortalities. 
The primary aim of this study was to address the above deficit by investigating the immediate (during fishing) and short-term (over $4 \mathrm{~d}$ ) fate of the various species traditionally discarded by commercial Platycephalus fuscus gillnetters. A secondary aim was to use this information to identify some of the key deleterious environmental, biological and/or technical factors, and ways that these might be mitigated via changes to existing operational and/or onboard handling procedures.

\section{MATERIALS AND METHODS}

Monitoring site and collection of controls. The work was done in Tuggerah Lake, NSW, Australia, between April and June 2008. One week prior to fishing, eight 10001 polyethylene (PE) holding tanks were located on the bank of the lake and supplied with local, flowthrough seawater (at a maximum rate of $631 \mathrm{~min}^{-1}$ ) and air. Sixty $2.5 \mathrm{~m}$ steel stanchions were secured approximately $2 \mathrm{~m}$ apart in 2 parallel lines in the lake at a depth of $1.5 \mathrm{~m}$, within $500 \mathrm{~m}$ of the holding tanks (termed the monitoring site). Each row of stanchions had $90 \mathrm{~m}$ of $10 \mathrm{~mm} \varnothing$ rope attached horizontally at a level corresponding with the average low tide. This configuration was used to secure up to 150 large $(0.5 \mathrm{~m} \varnothing \times 0.7 \mathrm{~m})$ and 30 small $(0.3 \mathrm{~m} \varnothing \times 0.4 \mathrm{~m})$ cages made from polyvinyl chloride (PVC) buckets with lids and clips at the top to facilitate attachment to the rope. Lateral windows were positioned near the middle of each cage and covered by $6 \mathrm{~mm}$ PVC mesh (for more details, see Uhlmann \& Broadhurst 2007, Broadhurst et al. 2008a). The position of the windows in the large cages meant that each held 301 of water and could be used to transport fish from one location to the other. The smaller cages were designed to fit into water-filled, 701 rectangular PVC containers during transport.

Several months prior to starting the experiment, approximately 200 Acanthopagrus australis and Girella tricuspidata were collected from estuaries near Coffs Harbour, NSW, using hook and line and smallmeshed seines and then housed at the National Marine Science Centre (NMSC) aquaria. All fish were handled, transported, fed and monitored for mortalities according to the procedures outlined by Broadhurst et al. (1997). Three days before the start of the experiment, the captive A. australis and G. tricuspidata were transferred from the NMSC and distributed among the 8 holding tanks at Tuggerah Lake. Some Synaptura nigra and intact Portunus pelagicus were also collected from nets set in the lake and similarly placed into holding tanks to recover for at least $5 \mathrm{~d}$. These captive fish and crabs were eventually used as controls (see below).
Fishing protocol and experimental design. Fishing was done using a chartered Platycephalus fuscus gillnet dory ( $5 \mathrm{~m}$ ), equipped with 2 gillnets and crewed by 1 fisher. Each net was made from $80 \mathrm{~mm}$ polyamide multimonofilament mesh (0.41 mm $\varnothing$ twine) secured at a hanging ratio of 0.5 along a $725 \mathrm{~m}$ headline and footrope, and had a depth of 16 meshes (stretched depth of $1.3 \mathrm{~m}$ ). At between 16:45 and 17:00 h on each of 11 nights (separated over 29 d), the 2 gillnets were consecutively deployed, mostly in a straight line, so that the end of the first net and the start of the second were within $20 \mathrm{~m}$. The nets were left to fish overnight before the fisher travelled back to the start of the first net and began manual retrieval at dawn (05:50 to 06:05 h), over between 1 and $3 \mathrm{~h}$.

During retrieval, all teleosts were removed from the nets by the fisher. Based on their MLS, Platycephalus fuscus were classified as either retained or discarded. Along with the remaining species comprising bycatch, the latter group was further separated into dead and live categories. For some deployments, up to 8 live Acanthopagrus australis and 5 live Girella tricuspidata, were randomly sampled for blood (following the methods described by Broadhurst et al. 2005) within 1 min of being removed from the gillnets, before being measured (to the nearest $\mathrm{mm}$ ) and then released back into the lake. The other remaining live individuals were 'discarded' directly into the large water-filled cages (4 fish cage $^{-1}$ for nearly all deployments) secured to a research dory tied alongside the gillnetter. Most A. australis, G. tricuspidata and Synaptura nigra were caged with their conspecifics, while all other species were mixed. As per conventional fishing, Portunus pelagicus were left entangled in the meshes until both gillnets had been completely retrieved, after which they were removed and undersize specimens individually placed into the small cages immersed in water-filled 75 l PVC containers onboard the research dory. All cages containing fish were transferred in the research dory to the monitoring site immediately after the last net was removed. During transfer, the water in each cage was regularly exchanged and maintained at the same quality as the deployment site. None of the discards were exposed to air during transfer.

Wherever possible, to control for the effects of caging on the various meshed-and-discarded species, untreated Acanthopagrus australis, Girella tricuspidata, Synaptura nigra and Portunus pelagicus were concomitantly monitored in appropriate separate cages. Specifically, within 30 min of the last discarded catches being secured to the line, the appropriate fish in the 8 holding tanks on the bank of the lake were anesthetised (using $35 \mathrm{mg} \mathrm{l}^{-1}$ of ethyl-p-amino benzoate), removed and placed into separate cages 
located on the research dory at the same stocking densities as the meshed-and-discarded fish. P. pelagicus were simply removed by hand from the holding tanks and individually placed into the small cages. These controls were then transferred to the monitoring site and clipped to the line.

All caged organisms were offered food and monitored for mortalities every $24 \mathrm{~h}$ over $4 \mathrm{~d}$. At each monitoring time any dead animals were removed, and for Acanthopagrus australis and Girella tricuspidata they were replaced with live (lower caudal fin clipped) individuals from the holding tanks to preserve caging density. All dead and live caged individuals at the end of $4 \mathrm{~d}$ were measured before healthy individuals with no obvious signs of infection were returned to the holding tanks for subsequent use as controls or stock fish, while others were released. Some A. australis and G. tricuspidata were angled near the monitoring site and sampled for blood (within 2 min of capture) as above before being released.

Data collected and analyses. The data collected from each gillnet during each deployment included the location, start and finish time of fishing; the time that the first and fourth fish were removed and placed into the same cage (to provide an average time for all fish in each cage); the air exposure of catches; and the numbers and weights of retained, discarded and total catches and their status (alive vs. dead). A Greenspan EC350 data logger was attached to the end of one gillnet and used to record temperature and salinity at 15 min intervals. The means were used to provide a datum for these variables for each deployment. Similarly, a Horiba U10 water-quality meter was used to record replicate readings of water temperature, dissolved $\mathrm{O}_{2}$ (DO) and salinity in the lake during the retrieval of each gillnet, and at the monitoring site.

The blood samples collected from the meshed and angled Acanthopagrus australis and Girella tricuspidata were analysed for concentrations of plasma glucose $\left(\mathrm{mmol} \mathrm{l}^{-1}\right)$ and cortisol $\left(\mathrm{ng} \mathrm{ml}^{-1}\right)$ to provide indices of acute stress. Glucose concentrations were obtained by means of colorimetric kits (Roche Diagnostics) using an enzymatic spectrophotometric assay done according to the manufacture's specifications, while plasma cortisol was ascertained by radioimmunoassay (according to the methods of Pankhurst \& Sharples 1992).

All statistical analyses were done separately for each species. The hypothesis of no differences in plasma glucose and cortisol concentrations between meshed and angled (baseline estimates) fish was investigated using appropriate 1-factor analyses of variance (ANOVA). The biological, environmental and technical covariates measured during each replicate deployment of the 2 gillnets were summarized and assessed for variability. Potentially important covariates were subsequently chosen (see 'Results') for inclusion as fixed effects in mixed-effects logistic models fitted to the binary end point of alive or dead. These models were applied to individuals of species with sufficient numbers (defined as $>50$ ind.) (1) during removal from the gillnets (immediate mortality) and (2) after being caged for $4 \mathrm{~d}$ (short-term mortality). The random factors of 'deployments' and 'nets' were also considered in both models, along with 'cages' in the latter. Models were fitted using the lmer function from the lme4 package of the $\mathrm{R}$ statistical language. The most parsimonious fit was chosen as the model with lowest Akaike's Information Criterion and the statistical significance of covariates was assessed via permutation tests. For consistency across all model fits, random effects terms were included in the preferred model whenever they were estimated to be present (i.e. nonzero).

Where appropriate, overall (unpartitioned) percentage mortalities were calculated for the key species by combining immediate and short-term estimates. These were obtained by first calculating overall survival probability, as given by the product of immediate and short-term survival probabilities. The subsequent mortality estimates that were obtained ignore all covariates (except random effects), but are nonetheless meaningful if the experimental deployments are considered to be a representative sample from the hypothetical population of all possible deployments in this gillnet fishery. Standard errors were calculated for immediate and short-term mortalities and then combined to provide an overall estimate using the delta method (Casella \& Berger 1990).

\section{RESULTS}

The mean total, retained and discarded catches across the 11 deployments were typical of those normally experienced in this fishery (Tables 1 \& 2). In total, 2968 organisms were caught, of which 1430 comprised legal Platycephalus fuscus (1325) and Portunus pelagicus (105). A total of 1470 discarded individuals from 16 species were assessed for their mortalities, although more than $90 \%$ of the discards comprised just 5 species: Girella tricuspidata (46.9\%), Synaptura nigra (20.5\%), Acanthopagrus australis (10.9\%), Pseudorhombus arsius (7.4\%) and Platycephalus fuscus $(5.2 \%)$ (Table 2$)$. The majority of caught $S$. nigra and $A$. australis, and approximately 33,50 and $60 \%$ of caught $P$. pelagicus, $G$. tricuspidata and $P$. arsius, respectively, were smaller than their MLS (Table 1). By comparison, the majority $(94.5 \%)$ of caught $P$. fuscus were legal size. 
Table 1. Summary of mean $( \pm \mathrm{SD})$ key environmental, technical and biological variables collected during the 11 deployments of the 2 gillnets. Minimum legal total (MLTL) and carapace (MLCL) lengths (in $\mathrm{cm}$ ) are provided for the key discarded teleosts and Portunus pelagicus, respectively. Deployment duration refers to the period between when the gear was completely deployed and the start of retrieval. DO: dissolved $\mathrm{O}_{2}$

\begin{tabular}{|c|c|}
\hline Variable & Measured \\
\hline \multicolumn{2}{|l|}{ Environmental } \\
\hline \multicolumn{2}{|l|}{$\begin{array}{l}\text { Water quality at the deployment site: } \\
\text { Temperature }\left({ }^{\circ} \mathrm{C}\right)\end{array}$} \\
\hline Bottom & $16.7 \pm 0.9$ \\
\hline Surface & $16.3 \pm 1.7$ \\
\hline \multicolumn{2}{|l|}{ Salinity (psu) } \\
\hline Bottom & $21.9 \pm 2.8$ \\
\hline Surface & $17.5 \pm 2.3$ \\
\hline $\mathrm{DO}\left(\mathrm{mg} \mathrm{l}^{-1}\right)$ & $8.3 \pm 0.9$ \\
\hline \multicolumn{2}{|l|}{ Water quality at the monitoring site: } \\
\hline Water temperature $\left({ }^{\circ} \mathrm{C}\right)$ & $16.8 \pm 1.6$ \\
\hline Salinity (psu) & $20.9 \pm 4.8$ \\
\hline $\mathrm{DO}\left(\mathrm{mg} \mathrm{l}^{-1}\right)$ & $8.2 \pm 1.3$ \\
\hline \multicolumn{2}{|l|}{ Catch air exposure (h) } \\
\hline Teleosts & $<0.03$ \\
\hline Portunus pelagicus & $2.5 \pm 1.4$ \\
\hline Air temperature during caging $\left({ }^{\circ} \mathrm{C}\right)$ & $14.9 \pm 2.4$ \\
\hline \multicolumn{2}{|l|}{ Technical } \\
\hline Depth of fishing (m) & $2.5 \pm 0.4$ \\
\hline Deployment duration (h) & $13.4 \pm 0.5$ \\
\hline Maximum soak time of caged fish (h) & $13.8 \pm 0.6$ \\
\hline \multicolumn{2}{|l|}{ Biological } \\
\hline Total catch (no.) & $134.9 \pm 68.3$ \\
\hline Retained catch (no.) & $66.7 \pm 40.8$ \\
\hline \multicolumn{2}{|l|}{ Size of key discards $(\mathrm{cm})$ : } \\
\hline Girella tricuspidata $(\mathrm{MLTL}=27)$ & $\begin{array}{r}27.3 \pm 3.3 \\
(\mathrm{n}=690)\end{array}$ \\
\hline Synaptura nigra $(\mathrm{MLTL}=25)$ & $\begin{array}{r}16.4 \pm 2.3 \\
(\mathrm{n}=302)\end{array}$ \\
\hline Acanthopagrus australis $(\mathrm{MLTL}=25)$ & $\begin{array}{r}22.0 \pm 1.9 \\
(\mathrm{n}=161)\end{array}$ \\
\hline Pseudorhombus arsius $(\mathrm{MLTL}=25)$ & $\begin{array}{r}23.3 \pm 3.7 \\
(\mathrm{n}=109)\end{array}$ \\
\hline Platycephalus fuscus (MLTL = 33) & $\begin{array}{c}30.4 \pm 4.6 \\
(\mathrm{n}=77)\end{array}$ \\
\hline Portunus pelagicus $(\mathrm{MLCL}=6)$ & $\begin{array}{l}6.1 \pm 5.9 \\
(\mathrm{n}=51)\end{array}$ \\
\hline
\end{tabular}

The various environmental parameters collected during the capture and monitoring of discards were comparable between the deployment and monitoring sites, and encompassed the species' natural tolerance ranges (Table 1). Most variables remained consistent among deployments with low variability; the few exceptions included salinity and the sizes of discards and, to a lesser extent, the water temperature during fishing (Table 1). While the number of organisms caught and the air temperature during caging were also quite variable, these were not considered likely to impact on mortality because all fish were (1) consid- ered physically independent of each other in terms of their location in meshes, and (2) caged within 2 min of emersion (Table 1). Based on the above, water temperature and salinity and the TL of discards were selected for inclusion as fixed parameters in the various mixedeffects logistic models to explain immediate and shortterm mortalities.

\section{Immediate mortalities and stress}

Immediate mortalities of discards (pooled across all deployments) ranged between 0 (Portunus pelagicus) and $70 \%$ (Platycephalus fuscus) for those species represented by reasonable sample sizes (Table 2). Mixedeffects models were fitted for the 5 species comprising $90 \%$ of the discards, and for each species the preferred model contained one of the fixed covariates. The permutation test showed that 2 of the covariates were significantly associated with the mortality of 3 species, including water temperature during fishing for Girella tricuspidata $(\mathrm{p}=0.035)$ and Pseudorhombus arsius $(\mathrm{p}=$ $0.030)$, and TL for Synaptura nigra $(p=0.049)$. Specifically, for the range of temperatures recorded (15 to $18^{\circ} \mathrm{C}$ ), the probabilities of $G$. tricuspidata and P. arsius being dead in the gillnets during retrieval increased from $<0.01$ to 0.39 and 0.96 , respectively, notwithstanding considerable uncertainty in these estimates as shown by the confidence bounds (Fig. 1a,b). By comparison, a negative relationship was observed between the TL of $S$. nigra and their immediate mortality, with an estimated probability of 0.14 for the smallest individuals ( $12 \mathrm{~cm}$ TL) decreasing to $<0.01$ for those longer than the MLS of $25 \mathrm{~cm}$ (Fig. 1c).

While not significant, the water temperature and salinity of the lake during fishing were included in the models to explain the immediate mortality of Platycephalus fuscus ( $\mathrm{p}=0.14)$ and Acanthopagrus australis ( $\mathrm{p}=0.07)$. As with Pseudorhombus arsius and Girella tricuspidata, warmer water corresponded to an increase in log-odds mortality of $P$. fuscus, while increasing salinity (19.4 to $27.3 \mathrm{psu}$ ) caused the opposite effect in A. australis.

Samples of blood were collected from 16 and 12 meshed Acanthopagrus australis and Girella tricuspidata caught during 8 and 6 deployments, respectively. Five specimens of each species were also angled close to the monitoring sites (to provide baseline estimates). One-factor ANOVA detected significant differences in mean \pm SE plasma cortisol between meshed and angled $A$. australis $\left(81.6 \pm 24.8\right.$ vs. $13.1 \pm 4.9 \mathrm{ng} \mathrm{ml}^{-1}$; $\left.F_{1,17}=5.2, \mathrm{p}=0.035\right)$ and $G$. tricuspidata $(128.8 \pm 29.2$ vs. $\left.5.3 \pm 1.7 \mathrm{ng} \mathrm{ml}^{-1} ; F_{1,14}=38.9, \mathrm{p}=0.00002\right)$. Concentrations of plasma glucose were not significantly different between groups for $A$. australis $(7.1 \pm 1.0$ vs. $2.7 \pm$ 
$0.3 \mathrm{mmol} \mathrm{l}^{-1} ; F_{1,19}=4.3, \mathrm{p}=0.052$ ), and less divergent for $G$. tricuspidata $\left(2.7 \pm 0.7\right.$ vs. $1.9 \pm 0.2 \mathrm{mmol} \mathrm{l}^{-1}$; $F_{1,15}=0.14 ; \mathrm{p}=0.71$ ).

\section{Short-term mortalities}

Of the 1470 ind. assessed for their immediate mortalities, 570 (11 species) were subsequently discarded alive into the cages (Table 2). Control individuals of 4 species, including Acanthopagrus australis ( $\mathrm{n}=100)$, Girella tricuspidata $(\mathrm{n}=108)$, Portunus pelagicus ( $\mathrm{n}=$ $41)$ and Synaptura nigra $(\mathrm{n}=18)$ were similarly caged and monitored during 10, 9, 9 and 4 deployments, respectively. None of the controls died. By comparison, short-term mortalities (pooled across all deployments) of the most abundant meshed-and-discarded species ranged between 0 (Meuschenia trachylepis and Pseudorhombus arsius) and 29\% (A. australis) and, except for $P$. pelagicus (for which all of the few deaths occurred within $24 \mathrm{~h}$ ), remained fairly protracted over the $4 \mathrm{~d}$ monitoring period (Fig. 2, Table 2). A. australis and $P$. pelagicus were the only species that had proportionally greater short-term than immediate mortalities (Table 2).

Mixed-effects logistic models were attempted for the 5 key species, but were successfully converged for only Acanthopagrus australis and Girella tricuspidata. In addition to the random effects of nets, deployments and cages, the parsimonious models for these 2 species included a significant fixed effect of water temperature ( $p=0.005)$ and TL $(p=0.026)$, respectively during fishing. These covariates manifested as a significant increase in the probability of $A$. australis dying over the short term (from 0.05 to 0.46 ) across the range of water temperatures $\left(15\right.$ to $\left.18^{\circ} \mathrm{C}\right)$ experienced during fishing, and a significant reduction in the mortality of G. tricuspidata (from 0.26 to 0.04 ) with increasing TL (21 to $38 \mathrm{~cm})$ (Fig. 3).

\section{Overall mortalities}

Estimates of overall (unpartitioned) mortality were made for the 7 most abundant species (Table 2). There were considerable inter-specific differences with large total percentages of Platycephalus fuscus, Pseudorhombus arsius and Acanthopagrus australis dying (approximately 45 to $77 \%$ ), and comparatively lower rates for Girella tricuspidata, Synaptura nigra, Portunus pelagicus and Meuschenia trachylepis (approximately 6 to $17 \%$ ).

\section{DISCUSSION}

In addition to the coarse mechanical interactions that occur during capture in net-based fishing gears, key environmental and biological factors often have strong concomitant impacts on the damage and mortality of discards (Davis 2002, Broadhurst et al. 2006a). The results from the present study support this trend, with water temperature and the size of individuals identified as significant covariates explaining the immediate and short-term fatalities of meshed-and-discarded Acanthopagrus australis, Girella tricuspidata, Synap-

Table 2. Numbers of deployments (D) and the associated dead and live meshed-and-discarded species and their observed partitioned mortality (\%M) immediately (all individuals) during gillnet retrieval and at the end of a $4 \mathrm{~d}$ monitoring period (shortterm) in cages (subsample of catches) and, where appropriate, estimates of overall mortality with associated SE in parentheses. -: not applicable or insufficient data

\begin{tabular}{|c|c|c|c|c|c|c|c|c|c|}
\hline Species & \multicolumn{4}{|c|}{ Immediate mortality } & \multicolumn{4}{|c|}{ Short-term mortality } & $\begin{array}{c}\text { Overall mortality } \\
(\%)\end{array}$ \\
\hline Girella tricuspidata & 11 & 663 & 27 & 3.9 & 10 & 184 & 30 & 14.0 & $17.4(3.2)$ \\
\hline Synaptura nigra & 10 & 264 & 38 & 12.6 & 7 & 100 & 4 & 3.8 & $15.9(3.7)$ \\
\hline Acanthopagrus australis & 11 & 122 & 39 & 24.2 & 11 & 74 & 30 & 28.8 & $44.6(7.1)$ \\
\hline Pseudorhombus arsius & 8 & 41 & 68 & 62.4 & 8 & 38 & 0 & 0.0 & $62.4(12.1)$ \\
\hline Platycephalus fuscus & 7 & 23 & 54 & 70.1 & 6 & 17 & 5 & 22.7 & $76.9(7.8)$ \\
\hline Portunus pelagicus & 10 & 51 & 0 & 0.0 & 10 & 48 & 3 & 5.9 & $5.9(3.3)$ \\
\hline Meuschenia trachylepis & 8 & 43 & 3 & 6.5 & 5 & 24 & 0 & 0.0 & $6.5(3.9)$ \\
\hline Rhabdosargus sarba & 2 & 2 & 0 & 0.0 & 2 & 0 & 2 & 100.0 & - \\
\hline Macquaria colonorum & 6 & 5 & 3 & 37.5 & 4 & 3 & 2 & 40.0 & - \\
\hline Sillago ciliata & 4 & 3 & 3 & 50.0 & 3 & 2 & 1 & 33.3 & - \\
\hline Gerres subfasciatus & 1 & 3 & 0 & 0.0 & 1 & 0 & 3 & 100.0 & - \\
\hline Trygonoptera testacea & 5 & 9 & 1 & 10.0 & - & - & - & - & - \\
\hline Valamugil georgii & 1 & 1 & 0 & 0.0 & - & - & - & - & - \\
\hline Mugil cephalus & 1 & 0 & 2 & 100.0 & - & - & - & - & - \\
\hline Argyrosomus japonicus & 1 & 0 & 1 & 100.0 & - & - & - & - & - \\
\hline Pseudocaranx dentex & 1 & 0 & 1 & 100.0 & - & - & - & - & - \\
\hline
\end{tabular}



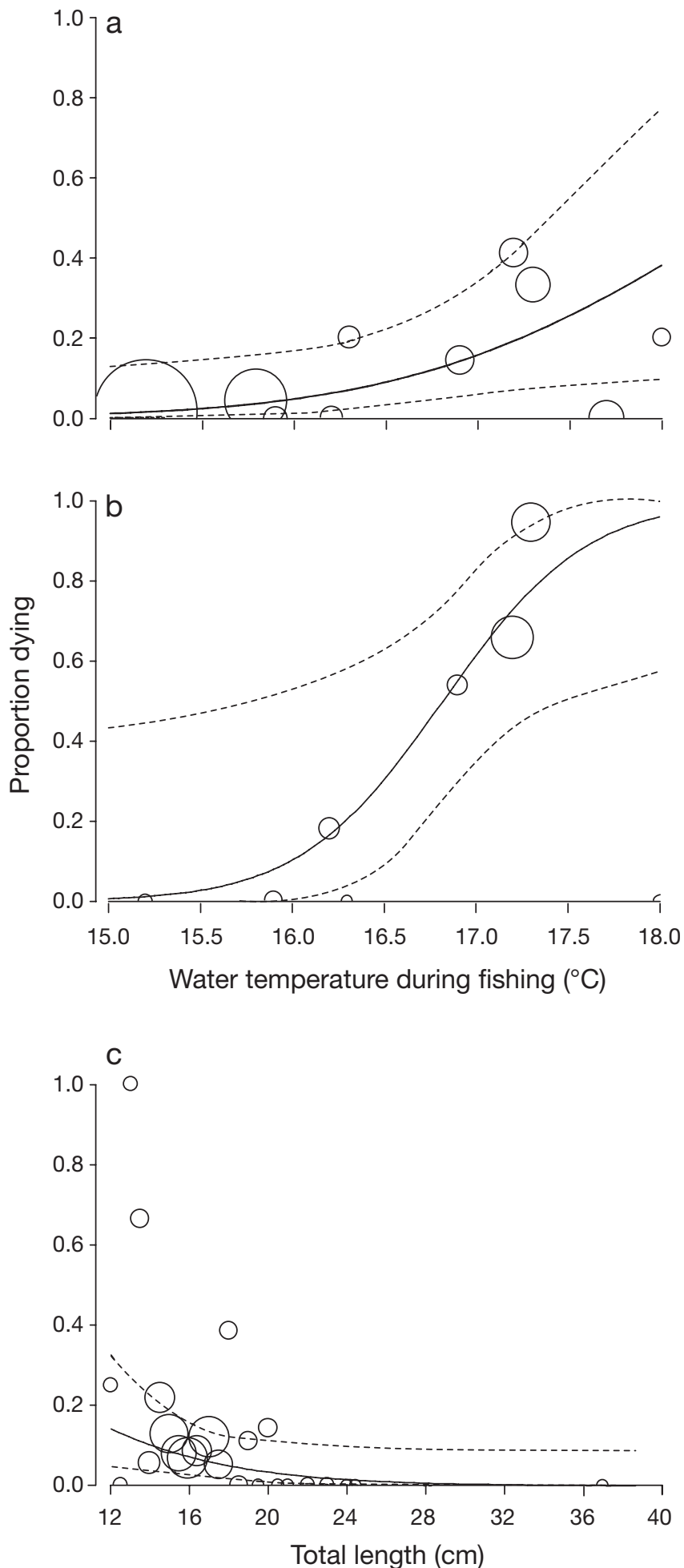

Fig. 1. Logistic regression fits of statistically significant covariates affecting immediate mortality of (a) Girella tricuspidata, (b) Pseudorhombus arsius and (c) Synaptura nigra during conventional deployments of a gillnet in Tuggerah Lake. Solid and dashed lines: maximum-likelihood fit estimated by the mixed-effects model and 95\% confidence intervals, respectively. Area of the plotting symbol (O) is proportional to sample size

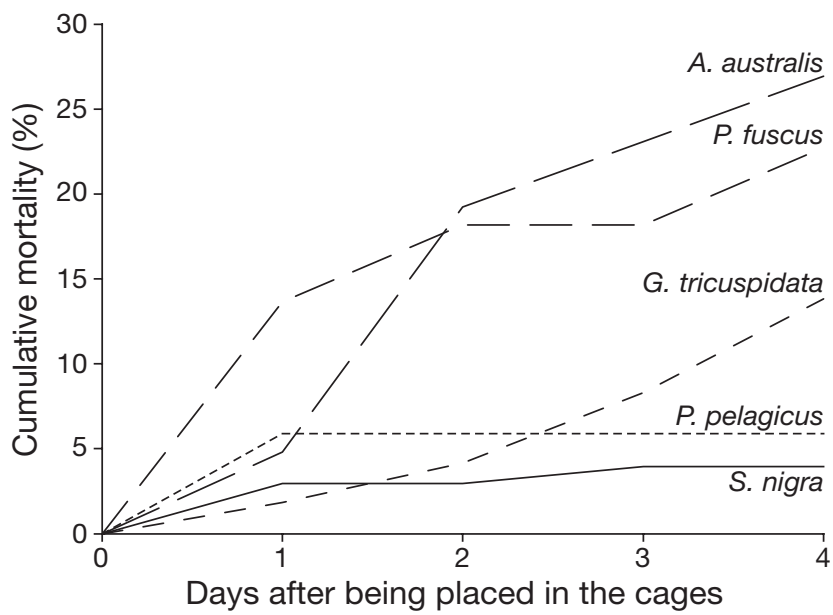

Fig. 2. Cumulative temporal mortalities of meshed-anddiscarded (into cages) Acanthopagrus australis, Platycephalus fuscus, Girella tricuspidata, Portunus pelagicus and Synaptura nigra

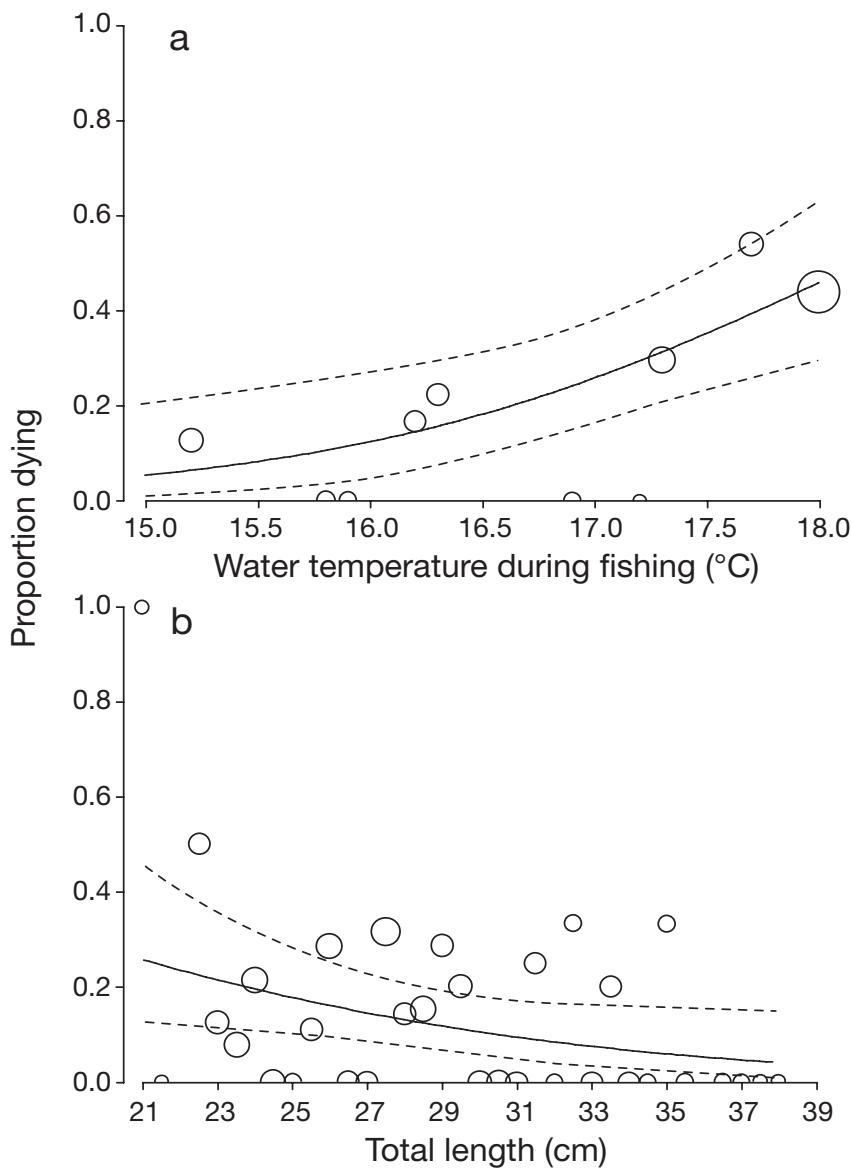

Fig. 3. Logistic regression fits of statistically significant covariates affecting short-term mortality of (a) Acanthopagrus australis and (b) Girella tricuspidata after being meshed, discarded alive into cages and then monitored for $4 \mathrm{~d}$ in Tuggerah Lake. Solid and dashed lines: maximum-likelihood fit estimated by the mixed-effects model and $95 \%$ confidence intervals, respectively. Area of the plotting symbol $(O)$ is proportional to sample size 
tura nigra and Pseudorhombus arsius. The importance of these parameters can be explained in terms of their cumulative impact on species-specific physiological and physical responses to the capture mechanisms.

Like most gillnets, the $80 \mathrm{~mm}$ configurations examined in this study selected the key teleosts across discrete ranges of sizes that were closely correlated to their maximum girth in relation to the mesh perimeter (i.e. 160 mm; Broadhurst et al. 2006b). Further, nearly all fish penetrated multiple meshes along their anterior bodies, with some completely wrapped in netting, which presumably occurred after they entered the first mesh and then struggled to escape (Hamley 1975). Most of these individuals sustained at least some abrasive-type injuries (e.g. loss of scales and dermis) from the twine but, of greater immediate consequence, restrictions to their operculum and/or gills which would have compromised ventilation, carbon dioxide secretion and aerobic respiration. It is likely that in some cases these metabolic costs were sufficient to cause suffocation and death.

For most species, the impacts of the catching mechanisms would have been exacerbated by warmer water. Depending on species-specific tolerances, increasing temperatures evoke a range of physiological disturbances at the cellular and whole animal levels, including a higher metabolic rate and demand for oxygen; the saturation of which paradoxically decreases (Pörtner 2002). Such temperature-related effects have been demonstrated to significantly increase the initial mortality of a range of teleosts discarded after capture by various fishing gears (for reviews see Davis 2002, Broadhurst et al. 2006a, Arlinghaus et al. 2007), including gillnets (Bettoli \& Scholten 2006).

In the present study, warmer water had an immediate impact on the mortality of Girella tricuspidata and Pseudorhombus arsius during fishing, but for Acanthopagrus australis the consequences were more protracted. Broadhurst et al. (2008b) observed similar temporal differences in fatalities between $A$. australis and other teleosts after contact with jellyfish during trawling, possibly reflecting a delayed response to cumulative stressors. The proportionally greater rate of shortterm, rather than immediate deaths, compared to all other abundant teleosts further supports this hypothesis. Equally likely, however, are variations among species-specific tolerances to pathogens that often proliferate as temperature increases to an optimum (e.g. Holt et al. 1975, Crossin et al. 2008). Although no histopathology was done, almost all caged-and-monitored $A$. australis had clear net marks around their anterior bodies and obvious signs of infection.

While the observed correlations between temperature and mortality for some of the key species corroborate previous research, an important difference here is that the range of temperatures was quite small (e.g. $3^{\circ} \mathrm{C}$ ). Most other relevant studies have isolated significant effects across a range of more than $10^{\circ} \mathrm{C}$ (e.g. Gustaveson \& Wydoski 1991, Murphy et al. 1995, Wilde et al. 2000, Dempson et al. 2002, Bettoli \& Scholten 2006). It is clear, however, that for some species there may be acceptable thresholds above which effects escalate quite quickly (e.g. Dempson et al. 2002, Wilde et al. 2000). For example, Wilde et al. (2000) noted a rapid increase in mortality among striped bass Morone saxatilis that were angled and released in water temperatures greater than $16^{\circ} \mathrm{C}$. Similarly, Bettoli \& Scholten (2006) observed that $71 \%$ of paddle fish Polyodon spathula died in gillnets during extended deployments in an average water temperature of $17^{\circ} \mathrm{C}$, compared to only $7 \%$ at $11^{\circ} \mathrm{C}$. It is possible that the temperatures observed here $\left(15\right.$ to $\left.18^{\circ} \mathrm{C}\right)$ encompassed comparable critical limits for Girella tricuspidata, Pseudorhombus arsius and Acanthopagrus australis.

Although not significant, a reduction in salinity also affected Acanthopagrus australis, corresponding to an increase in their log-odds immediate mortality. The salinities observed in Tuggerah Lake were within the optimal range for most sparids (12 to 28 psu; Partridge \& Jenkins 2002), but the lower levels may have required $A$. australis to increase their metabolic rate to achieve osmotic balance and, as a corollary, their susceptibility to other stressors. Comparable relationships between salinity and immediate mortality have been observed for other local teleosts (including southern herring Herklotsichthys castelnaui and Port Jackson glassfish Ambassis jacksoniensis) discarded during trawling (Broadhurst et al. 2008b).

The impacts of environmental parameters like salinity and temperature would be exacerbated in smaller fish since they are physiologically and physically more vulnerable (Broadhurst et al. 2008b). For example, because rates of heating are negatively correlated to body size, warmer water might have a relatively greater effect on small individuals (Spigarelli et al. 1977). Temperature effects would also be greater in those small fish with a large surface area relative to their mass and this relationship may explain the significant correlation between TL and the immediate mortality of Synaptura nigra (i.e. a flatfish). A concomitant explanation for the protracted deaths of Girella tricuspidata is the dependence of size on their removal from meshes. Specifically, like Broadhurst et al. (2008a), we observed that most fish with girths smaller than the mesh perimeter were quickly pushed forwards by the fisher, while larger individuals were more slowly untangled backwards. Forcing G. tricuspidata through meshes close to their maximum girth would have caused at least some injuries that may have contributed towards their mortality. 
The method of removal from meshes might also account for the few deaths $(6 \%)$ to Portunus pelagicus. Uhlmann et al. (2009) identified that limb loss and any associated unsealed wounds during forced removal from gillnet meshes were clear predictors of mortality in this species, with the latter impact resulting in $100 \%$ fatalities, mostly within $24 \mathrm{~h}$. Although nearly all individuals caught in Tuggerah Lake were left entangled in the nets and exposed to air for an average of $2.5 \mathrm{~h}$ before being removed, their untangling was done slowly and mostly without causing the loss of limbs. $P$. pelagicus appear very resilient to air exposure and so the few deaths that occurred within $24 \mathrm{~h}$ were attributed to some inadvertent wounding during removal.

While this study has quantified immediate and shortterm mortalities and isolated some of the explanatory covariates for key teleosts discarded during extended gillnet deployments, these estimates are by no means definitive. Unlike in the wild, all of the discards were caged and fed, and although the lack of mortalities to controls indicates no confounding effects, short-term mortalities may still have been underestimated. The few Acanthopagrus australis and Girella tricuspidata that were sampled for blood immediately after being removed from the gillnets had significantly elevated plasma cortisol, which for some individuals (e.g. up to 374 and $384 \mathrm{ng} \mathrm{ml}^{-1}$, respectively) were above the peak post-stress values recorded for many teleosts (e.g. Barton \& Iwama 1991). Glucose concentrations were not significantly different to baseline estimates, but the mean increase combined with the cortisol response, suggests the potential for further rises after discarding. Such acute capture-related stress could lead to tertiary effects, including a lower resistance to disease (Lupes et al. 2006) and/or ability to evade predation (Ryer 2002).

Notwithstanding the potential for other unaccounted fishing mortalities, the results provide clear direction for the management of this fishery. First, it is imperative that gillnet deployments are optimised according to the distribution and abundance of the targeted Platycephalus fuscus (and so reduce bycatch). Second, the strong correlation between water temperature and the mortality of Girella tricuspidata, Pseudorhombus arsius and Acanthopagrus australis could be used to more finely regulate effort. For example, rather than the current broad seasonal closures, fishing could be restricted (either entirely or via deployment duration) beyond a maximum water temperature (approximately 16 to $17^{\circ} \mathrm{C}$ ), and on an estuary-specific basis. Such an approach would greatly reduce mortalities to $P$. arsius and the abundant $A$. australis which, along with $P$. fuscus were the 3 species characterized by the highest total fatalities (>45\%). Lastly, while most undersize P. fuscus died across all temperatures, owing to the size selectivity of the current gillnet configurations (Broadhurst et al. 2003), these individuals represented only $5.5 \%$ of the total number caught and so their retention could be legally permitted as a defined proportion of overall catch. Combined with a willingness of fishers to carefully handle their discarded catches, the above strategies have the potential to considerably reduce unnecessary wastage in this fishery.

Acknowledgements. The research was funded by the NSW department of primary Industries and the Australian Fisheries and Research Development Corporation (Grant no. 2005/056). The experimental methods were approved by the NSW Animal Care and Ethics Committee (ACEC ref 05/10). We thank J. Brown for the use of his gillnetter, Tuggerah Lake fishers for their support, S. Soule, C. Dowling, L. Basset and S. McGrath for technical assistance.

\section{LITERATURE CITED}

Arlinghaus R, Cooke SJ, Lyman J, Policansky D and others (2007) Understanding the complexity of catch-and-release in recreational fishing: an integrative synthesis of global knowledge from historical, ethical, social and biological perspectives. Rev Fish Sci 15:75-167

Barton BA, Iwama GK (1991) Physiological changes in fish from stress in aquaculture with emphasis on the response and effects of corticosteroids. Annu Rev Fish Dis 1:3-26

Bettoli PW, Scholten GD (2006) Bycatch rates and initial mortality of paddle fish in a commercial gillnet fishery. Fish Res 77:343-347

> Broadhurst MK, Kennelly SJ, Barker DT (1997) Simulated escape of juvenile sand whiting (Sillago ciliata, Cuvier) through square-meshes: effects on scale-loss and survival. Fish Res 32:51-60

Broadhurst MK, Gray CA, Young DJ, Johnson DD (2003) Relative efficiency and size selectivity of bottom-set gill-nets for dusky flathead, Platycephalus fuscus and other species in New South Wales, Australia. Arch Fish Mar Res 50: $287-300$

Broadhurst MK, Gray CA, Reid DD, Wooden MEL, Young DJ, Haddy JA, Damiano C (2005) Mortality of key fish species released by recreational anglers in an Australian estuary. J Exp Mar Biol Ecol 321:171-179

Broadhurst MK, Suuronen P, Hulme A (2006a) Estimating collateral mortality from towed fishing gear. Fish Fish 7 : 180-218

Broadhurst MK, Dijkstra K, Reid DD, Gray CA (2006b) Utility of morphological data for key fish species in southeastern Australian beach-seine and otter-trawl fisheries: predicting mesh size and configuration. NZ J Mar Freshw Res 40:259-272

> Broadhurst MK, Millar RB, Brand CP, Uhlmann SS (2008a) Mortality of discards from southeastern Australian beach seines and gillnets. Dis Aquat Org 80:51-61

Broadhurst MK, Uhlmann SS, Millar RB (2008b) Reducing discard mortality in an estuarine trawl fishery. J Exp Mar Biol Ecol 364:54-61

Buchanan S, Farrell AP, Fraser J, Gallaugher P, Joy R, Routledge $R$ (2002) Reducing gill-net mortality of incidentally caught coho salmon. N Am J Fish Manage 22:1270-1275

Casella G, Berger RL (1990) Statistical inference. Duxbury Press, Pacific Grove, CA 
Crossin GT, Hinch SG, Cooke SJ, Welch DW and others (2008) Exposure to high temperature influences the behaviour, physiology, and survival of sockeye salmon during spawning migration. Can J Zool 86:127-140

Davis MW (2002) Key principles for understanding fish bycatch discard mortality. Can J Fish Aquat Sci 59: 1834-1843

Dempson JB, Furey G, Bloom M (2002) Effects of catch and release angling on Atlantic salmon, Salmo salar L., of the Conne River, Newfoundland. Fish Manag Ecol 9:139-147

Gray CA (2002) Management implications of discarding in an estuarine multi-species gill net fishery. Fish Res 56: 177-192

Gray CA, Johnson DD, Young DJ, Broadhurst MK (2004) Discards from the commercial gillnet fishery for dusky flathead, Platycephalus fuscus, in New South Wales, Australia: spatial variability and initial effects of change in minimum legal length of target species. Fish Manag Ecol 11:323-333

> Gray CA, Johnson DD, Broadhurst MK, Young DJ (2005a) Seasonal, spatial and gear-related influences on relationships between retained and discarded catches in a multispecies gillnet fishery. Fish Res 75:56-72

Gray CA, Broadhurst MK, Johnson DD, Young DJ (2005b) Influences of hanging ratio, fishing height, twine diameter and material of bottom-set gillnets on catches of dusky flathead Platycephalus fuscus and non-target species in New South Wales, Australia. Fish Sci 71: $1217-1228$

Gustaveson W, Wydoski RS (1991) Physiological response of largemouth bass to angling stress. Trans Am Fish Soc 120: 629-636

Hamley JM (1975) Review of gillnet selectivity. J Fish Res Board Can 32:1943-1969

Holt RA, Sanders JE, Zinn JL, Fryer JL, Pilcher KS (1975) Relation of water temperature to Flexibacter columnaris infection in steelhead trout (Salmo gairdneri), coho

Editorial responsibility: Bernd Sures,

Essen, Germany
(Oncorhynchus kisutch) and chinook (O. tshawytscha) salmon. J Fish Res Board Can 32:1553-1559

Lupes SL, Davis MW, Olla BL, Schreck CB (2006) Capturerelated stressors impair immune system function in sablefish. Trans Am Fish Soc 135:129-138

- Murphy MD, Heagey RF, Neugebauer VH, Gordon MD, Hintz JL (1995) Mortality of spotted seatrout released from gill-net or hook-and-line gear in Florida. N Am J Fish Manage 15:748-753

Pankhurst NW, Sharples DF (1992) Effects of capture and confinement on plasma cortisol concentrations in the snapper, Pagrus auratus. Aust J Mar Freshw Res 43:345-356

> Partridge GJ, Jenkins GI (2002) The effect of salinity on growth and survival of juvenile black bream (Acanthopagrus butcheri). Aquaculture 210:219-230

Pörtner HO (2002) Climate variations and the physiological basis of temperature dependent biogeography: systemic to molecular hierarchy of thermal tolerance in animals. Comp Biochem Physiol 132A:739-761

Ryer CH (2002) Trawl stress and escapee vulnerability to predation in juvenile walleye pollock: Is there an unobserved bycatch of behaviorally impaired escapees? Mar Ecol Prog Ser 232:269-279

Spigarelli SA, Thommes MM, Beitinger TL (1977) The influence of body weight on heating and cooling of selected Lake Michigan fishes. Comp Biochem Physiol A 56:51-57

Uhlmann SS, Broadhurst MK (2007) Damage and partitioned mortality of teleosts discarded from two Australian penaeid fishing gears. Dis Aquat Org 76:173-186

Uhlmann SS, Broadhurst MK, Paterson BD, Mayer DG, Butcher P, Brand CP (2009) Mortality and blood loss by blue swimmer crabs, Portunus pelagicus, after simulated capture and discarding from gillnets. ICES J Mar Sci 66: 455-461

Wilde GR, Mouneke MI, Bettoli PW, Nelson KL, Hysmith BT (2000) Bait and temperature effects on striped bass hooking mortality in freshwater. N Am J Fish Manag 20:810-815

Submitted: November 14, 2008; Accepted: April 3, 2009

Proofs received from author(s): June 5, 2009 